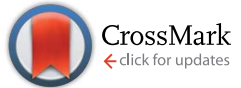

Cite this: Chem. Sci., 2015, 6, 1018

Received 2nd July 2014

Accepted 30th October 2014

DOI: $10.1039 / c 4 s c 01979 b$

www.rsc.org/chemicalscience

\section{Chelation-induced diradical formation as an approach to modulation of the amyloid- $\beta$ aggregation pathway $\dagger$}

\author{
Meghan R. Porter, ${ }^{a}$ Akiko Kochi, ${ }^{\text {bc }}$ Jonathan A. Karty, ${ }^{a}$ Mi Hee Lim*cd \\ and Jeffrey M. Zaleski*a
}

Current approaches toward modulation of metal-induced $A \beta$ aggregation pathways involve the development of small molecules that bind metal ions, such as $\mathrm{Cu}(॥)$ and $\mathrm{Zn}(॥)$, and interact with $\mathrm{A} \beta$. For this effort, we present the enediyne-containing ligand (Z)- $N, N^{\prime}$-bis[1-pyridin-2-yl-meth(E)-ylidene]oct-4ene-2,6-diyne-1,8-diamine (PyED), which upon chelation of $\mathrm{Cu}(\|)$ and $\mathrm{Zn}(\|)$ undergoes Bergmancyclization to yield diradical formation. The ability of this chelation-triggered diradical to modulate $A \beta$ aggregation is evaluated relative to the non-radical generating control pyridine-2-ylmethyl(2-\{[(pyridine-2-ylmethylene)-amino]-methyl\}-benzyl)-amine (PyBD). Variable-pH, ligand UV-vis titrations reveal $\mathrm{p} K_{\mathrm{a}}=3.81(2)$ for $\mathrm{PyBD}$, indicating it exists mainly in the neutral form at experimental $\mathrm{pH}$. Lipinski's rule parameters and evaluation of blood-brain barrier (BBB) penetration potential by the PAMPA-BBB assay suggest that PyED may be CNS+ and penetrate the BBB. Both PyED and PyBD bind $\mathrm{Zn}(\|)$ and $\mathrm{Cu}(॥)$ as illustrated by bathochromic shifts of their UV-vis features. Speciation diagrams indicate that $\mathrm{Cu}\left({ }^{\prime \prime}\right)-$ PyBD is the major species at $\mathrm{pH} 6.6$ with a nanomolar $K_{\mathrm{d}}$, suggesting the ligand may be capable of interacting with $\mathrm{Cu}(\mathrm{II})-\mathrm{A} \beta$ species. In the presence of $A \beta_{40 / 42}$ under hyperthermic conditions $\left(43^{\circ} \mathrm{C}\right)$, the radical-generating PyED demonstrates markedly enhanced activity $(2-24 \mathrm{~h})$ toward the modulation of $\mathrm{A} \beta$ species as determined by gel electrophoresis. Correspondingly, transmission electron microscopy images of these samples show distinct morphological changes to the fibril structure that are most prominent for $\mathrm{Cu}(\mathrm{II})-\mathrm{A} \beta$ cases. The loss of $\mathrm{CO}_{2}$ from the metal binding region of $A \beta$ in MALDI-TOF mass spectra further suggests that metal-ligand-A $\beta$ interaction with subsequent radical formation may play a role in the aggregation pathway modulation.

\section{Introduction}

Alzheimer's disease (AD) is the most common form of dementia, affecting over 24 million people worldwide. ${ }^{1}$ It is estimated that this number will nearly double by 2030 , partly due to demographic aging resulting from improved healthcare. ${ }^{1}$ The disease presence and progression are pathologically characterized by accumulation of misfolded amyloid- $\beta$ (A $\beta$ ) peptides deriving from $\beta$ - and $\gamma$-secretase cleavage of the amyloid precursor protein (APP) $)^{2-4}$ to produce $A \beta_{40}$ and $A \beta_{42}$ that selfassemble through hydrophobic interactions to form oligomers, protofibrils, fibrils, and ultimately, insoluble plaques..$^{4-6}$ It has

\footnotetext{
${ }^{a}$ Department of Chemistry, Indiana University, Bloomington, Indiana 47405, USA. E-mail: zaleski@indiana.edu

${ }^{b}$ Department of Chemistry, University of Michigan, Ann Arbor, Michigan 48109, USA ${ }^{c}$ Department of Chemistry, Ulsan National Institute of Science and Technology (UNIST), Ulsan 689-798, Korea.E-mail: mhlim@unist.ac.kr

${ }^{d}$ Life Sciences Institute, University of Michigan, Ann Arbor, Michigan 48109, USA

$\dagger$ Electronic supplementary information (ESI) available: Details of experimental procedures and supplementary figures and tables. See DOI: $10.1039 / \mathrm{c} 4 \mathrm{sc01979b}$
}

been proposed that $A \beta$ plaque accumulation may arise from an imbalance in $\mathrm{A} \beta$ production and clearance (i.e., amyloid cascade hypothesis);,7-9 accumulation of these peptides alone can impair neuronal mitochondrial function, leading to oxidative stress, inflammation, and the neurodegeneration commonly associated with $\mathrm{AD}$ (i.e., oxidative stress hypothesis). ${ }^{\mathbf{4 1 0}-12}$ In addition to self-aggregation, miscompartmentalization and dyshomeostasis of metals are found in $\mathrm{AD}$-afflicted brains. In particular, elevated levels of metals, such as $\mathrm{Cu}, \mathrm{Zn}$, and $\mathrm{Fe}$, are observed in $\mathrm{A} \beta$ plaques. ${ }^{3-5,13-19}$ Metal binding to $\mathrm{A} \beta$ is shown to facilitate peptide aggregation and in the case of redox active metal ions, reactive oxygen species (ROS) can be generated via Fenton-like reactions, leading to oxidative stress. ${ }^{4,5,17,19-24}$

On the basis of the observed metal ion dyshomeostasis, metal-A $\beta$ interaction, and metal-involved $A \beta$ reactivity, there has been considerable interest in the development of metal chelators capable of regulating metal ion distribution distribution and amyloid pathology. For example, the hydroxyquinoline-based antifungal drug clioquinol (CQ) decreased $A \beta$ deposits and showed improved cognition in Phase II clinical 
trials for $\mathrm{AD}$, in part due to its ability to inhibit binding of $\mathrm{Zn}$ (II) and $\mathrm{Cu}(\mathrm{II})$ to $\mathrm{A} \beta$ via chelation. ${ }^{25-27}$ Moreover, the second generation 8-hydroxyquinoline ionophore PBT2 also improved learning and memory by redistributing $\mathrm{Cu}$ (II) and $\mathrm{Zn}$ (II) and lowered cerebrospinal fluid levels of $A \beta$ in Phase II clinical trials. ${ }^{28,29}$

Although CQ and PBT2 have presented noticeable effects on metal redistribution and $A \beta$ clearance, the relationship between metal-associated $\mathrm{A} \beta$ (metal-A $\beta$ ) species and $\mathrm{AD}$ pathogenesis is still unclear, thus new efforts on developing chemical tools for specifically studying metal-A $\beta$ species have been made. ${ }^{21,24,30-33}$ For example, the rational design of chelators containing dimethylaniline and polydentate motifs using nitrogen and oxygen donor atoms for metal ions has led to blood-brain barrier (BBB) permeable compounds that modulate metal-induced $\mathrm{A} \beta$ aggregation, reduce $\mathrm{Cu}-\mathrm{A} \beta$ ROS formation, demonstrate antioxidant activity, and/or decrease metal-A $\beta$ toxicity in vitro. ${ }^{30,32-34}$

Our latest approach to bifunctional chelators for $\mathrm{A} \beta$ modification derives from drugs such Fe-Bleomycin or hydroxyl radical footprinting reagents that act via Fenton chemistry and perform $\mathrm{H}$-atom abstraction from the ribose ring of DNA leading to strand scission. ${ }^{35,36}$ Similarly, enediyne natural products such as calicheamicin that generate a potent 1,4-phenyl diradical also affect strand scission by $\mathrm{H}$-atom abstraction. Radical reactions of these types however, are not limited to DNA substrates. Rather, radical-mediated footprinting is an established methodology for evaluating protein structure via solvent accessible reactivity, ${ }^{37}$ as well as for mapping protein-protein and protein-DNA interactions. ${ }^{\mathbf{3 8 - 4 7}}$ Generation of ROS by reaction with redox active $\mathrm{Fe}, \mathrm{Cu}$, and $\mathrm{Mn}$ complexes ${ }^{38,48-58}$ in the presence of reductant leads to controlled backbone or side chain attack which can be used to evaluate regions of macromolecular interface. While ribose ring radical strand breaks in DNA are generally due to $\mathrm{H}$-atom abstraction from relatively weak tertiary $\mathrm{C}-\mathrm{H}$ bonds ${ }^{38}$ that are statistically plentiful and readily accessible, ${ }^{59} \mathrm{H}$-atom abstraction from proteins is more complex. Direct $\mathrm{H}$-abstraction from the $\alpha$-carbon and side chain-assisted $\mathrm{H}$-abstraction both lead to backbone cleavage, ${ }^{59-61}$ but poor solvent permeability and the statistical probability of extensive side chain oxidation make this process less prevalent. . $^{37,39,46,47,59,62}$ Somewhere between these limits lies calicheamicin which performs $\alpha$-H abstraction from the protector protein CalC at Gly-113, cleaving the protein in a radical self-resistance mechanism. ${ }^{63}$

With this backdrop, we envisioned a bifunctional agent that could attack $\mathrm{A} \beta$ aggregates by initially chelating $\mathrm{A} \beta$-bound metal ions to disrupt the peptide structure and subsequently using this chelation event to induce diradical formation that would further modify the remaining $\mathrm{A} \beta$ aggregates. We have shown that the compound ( $Z$ )- $N, N^{\prime}$-bis[1-pyridin-2-yl-meth $(E)$-ylidene] oct-4-ene-2,6-diyne-1,8-diamine (PyED) (Fig. 1) binds a wide array of metal ions such as $\mathrm{Mg}^{64} \mathrm{Cu}, \mathrm{Fe}$, and $\mathrm{Zn}$ and these complexes may be thermally activated to yield a potent 1,4-diradical intermediate. Our experience with enediyne activation via metal coordination ${ }^{64-66}$ and photochemical $^{67-69}$ diradical formation has taught us that these molecular frameworks are capable of both $\mathrm{H}$-atom abstraction ${ }^{\mathbf{6 4 , 6 6 , 6 7}}$ and addition/
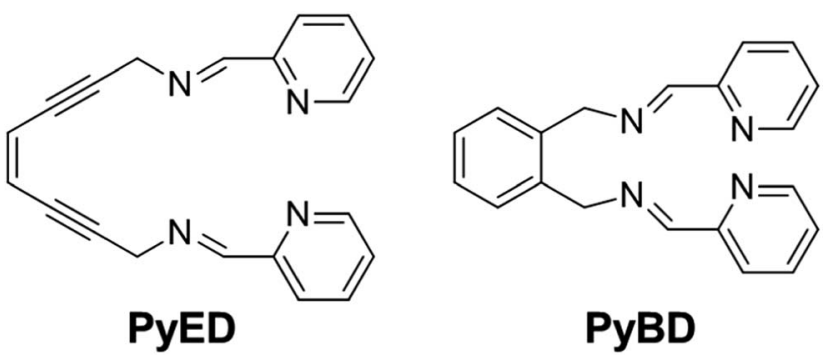

Fig. 1 Structures of radical-generating enediyne and cyclized control ligands employed for modulation of $A \beta$ species.

polymerization reactions ${ }^{\mathbf{6 8 , 6 9}}$ depending upon the substrate and radical-radical coupling proximity. Additionally, PyED has demonstrated enhanced activity under clinically relevant hyperthermic conditions $\left(42.5{ }^{\circ} \mathrm{C}\right) .^{70}$ Although hyperthermic treatments have not commonly been applied in the field of $\mathrm{AD}$, hyperthermia has been established as a method to enhance therapeutic efficiency when used in combination with other cancer treatments both in vitro ${ }^{71-75}$ and in vivo ${ }^{75-78}\left(\leq 45.5^{\circ} \mathrm{C}\right)$. Thus, herein we report the application of such reactions to metal-bound ( $\mathrm{Cu}(\mathrm{II}), \mathrm{Zn}(\mathrm{II})) \mathrm{A} \beta$ aggregates by administration of PyED at physiological $\left(37^{\circ} \mathrm{C}\right)$ and hyperthermic $\left(43{ }^{\circ} \mathrm{C}\right)$ temperatures relative to the non-radical generating control pyridine-2-ylmethyl-(2-\{[(pyridine-2-ylmethylene)-amino]methyl-benzyl)-amine, PyBD (Fig. 1).

\section{Results and discussion}

\section{Rationale and characterization of PyED and PyBD used for modulating metal-A $\beta$ species}

The reactive compounds PyED (chelation + radical generation) and PyBD (chelation alone) for the modulation of $\mathrm{A} \beta$ species were synthesized and characterized by their ${ }^{1} \mathrm{H},{ }^{13} \mathrm{C} \mathrm{NMR}$, and mass signatures according to literature precedent. ${ }^{64}$ Cyclization of PyED by $\mathrm{Cu}$ (II) or $\mathrm{Zn}$ (II) chelation was investigated in $\mathrm{MeOH}$ and occurs within $4 \mathrm{~h}$ at $37^{\circ} \mathrm{C}$ upon radical trapping with 1,4cyclohexadiene and extraction with $\mathrm{NaBH}_{4}$ (12 equiv.)/EDTA $(\mathrm{pH} 10.6) .{ }^{64}$ The ${ }^{13} \mathrm{C}$ NMR feature at $\delta 128 \mathrm{ppm}$ and ESI-MS $(\mathrm{m} / \mathrm{z}$ : 319.2 ) are diagnostic of cyclized product formation indicating PyED undergoes rapid radical formation in the presence of $\mathrm{Cu}$ (II) or Zn(II). Variable-pH UV-visible (UV-vis) titrations were conducted to evaluate the protonation state of the ligand in solution, particularly at physiologically relevant $\mathrm{pH}(\mathrm{pH}=$ 7.4). ${ }^{34,79,80}$ In light of the fact that PyED slowly generates reactive radicals at ambient temperature over the timescale of the measurement (4-5 h), speciation was determined using the nonreactive, cyclized control PyBD. Titration results indicate a single acid ionization constant $\left(\mathrm{p} K_{\mathrm{a}}\right)$ for PyBD $\left(\mathrm{p} K_{\mathrm{a}}=3.81(2)\right)$, suggesting that neutral and monoprotonated forms of the ligand may be present in solution depending on $\mathrm{pH}$. Furthermore, the solution speciation diagram reveals that PyBD is expected to exist mainly in the neutral form at pH 7.4 (Fig. 2).

In an effort to establish the drug-likeness of PyED and its potential to penetrate the $\mathrm{BBB}$, Lipinski's rule parameters $(\mathrm{MW}<450, c \log P<5.0, \mathrm{HBA}<10, \mathrm{HBD}<5)$ and the $\log \mathrm{BB}$ were 

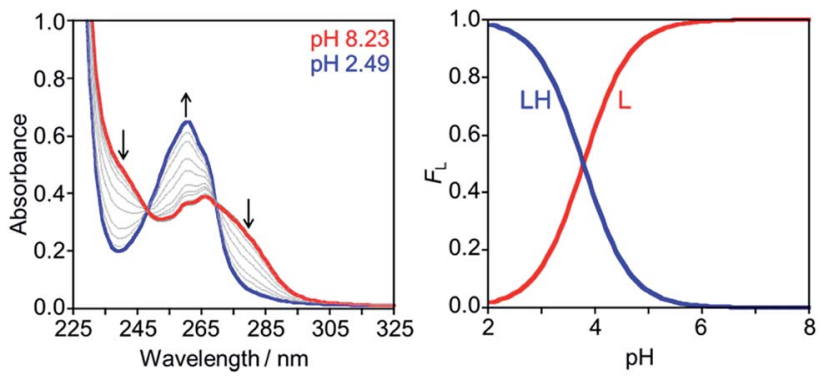

LH

$\rightleftharpoons \mathrm{L}+\mathrm{H}$

H

PyBD

$p K_{\mathrm{a}}^{\mathrm{a}} 3.81(2)$

Fig. 2 Solution speciation of PyBD $(50 \mu M)$. Left: UV-vis spectra in the range of $\mathrm{pH} 2-8$. Right: solution speciation diagram $\left(F_{\mathrm{L}}=\right.$ fraction of compound in given protonation state). Bottom: acidity constants of $L$ $(L=P y B D)$ with charges omitted for clarity. Speciation was performed at room temperature with $I=0.1 \mathrm{M} \mathrm{NaCl}$. ${ }^{a}$ Error in the last digit is indicated in parentheses.

Table 1 Values for Lipinski's rules and others for PyED

\begin{tabular}{lll}
\hline Calculation $^{a}$ & PyED & Lipinski rule parameters and others \\
\hline MW & 312.37 & 450 \\
$c \log P$ & 1.01 & 5.0 \\
HBA & 4 & 10 \\
HBD & 0 & 5 \\
PSA & 50.5 & $90 \AA^{2}$ \\
$\log$ BB & -0.464 & 0.3 (readily crosses the BBB) \\
& & -1.0 (poorly distributed in the brain) \\
$-\log P_{\mathrm{e}}{ }^{b}$ & $4.9 \pm 0.1$ & \\
CNS \pm prediction $^{c}$ & $\mathrm{CNS}+$ & $-\log P_{\mathrm{e}} 5.4(\mathrm{CNS}+)$ \\
& & $-\log P_{\mathrm{e}} 5.7$ (CNS-)
\end{tabular}

${ }^{a}$ MW, molecular weight; $c \log P$, calculated logarithm of the octanolwater partition coefficient; HBA, hydrogen-bond acceptor atoms; HBD, hydrogen-bond donor atoms; PSA, polar surface area; $\log \mathrm{BB}=$ $-0.0148 \times$ PSA $+0.152 \times c \log P 0.130 .{ }^{b}$ The values of $-\log P_{\mathrm{e}}$ were measured by the parallel artificial membrane permeability assay (PAMPA). ${ }^{c}$ CNS + compounds have the ability to permeate the BBB and target the CNS, while CNS- compounds have poor permeability through the BBB and therefore, their bioavailability into the CNS is considered minimal.

evaluated (Table 1). ${ }^{81-84}$ The resulting values $(\mathrm{MW}=312.37$, $c \log P=1.01, \mathrm{HBA}=4, \mathrm{HBD}=0)$ indicate PyED has drug-like characteristics as well as possible BBB permeability (Table 1). In order to verify the predicted ability of PyED to penetrate the $\mathrm{BBB}$, an in vitro PAMPA-BBB assay was performed following literature procedure..$^{34,81,85}$ Using the empirical classification for BBB-permeable molecules, the measured permeability value, $-\log P_{\mathrm{e}}$, for PyED $\left(-\log P_{\mathrm{e}}=4.9 \pm 0.1\right)$ suggests PyED may be likely to penetrate the BBB.

\section{Metal binding properties of PyED and PyBD}

Divalent metal binding of PyED and PyBD at $0{ }^{\circ} \mathrm{C}$ was demonstrated by bathochromic shifts of their UV-vis features (PyED $\lambda=264 \mathrm{~nm}$; PyBD $\lambda=272 \mathrm{~nm}$ ) upon addition of $\mathrm{ZnCl}_{2}$ or $\mathrm{CuCl}_{2}$ (1 equiv.) in ethanol (Fig. S1 $\dagger$ ). At 1 equiv. of $\mathrm{MCl}_{2}$, the absorption spectra of PyBD show the formation of distinct metallated species with larger bathochromic shifts observed for $\mathrm{Cu}$ (II) binding relative to $\mathrm{Zn}$ (II). For the more flexible chelate PyED, these shifts are somewhat less pronounced and indicate parallel, but slightly weaker ligand binding under these unactivating conditions $\left(0{ }^{\circ} \mathrm{C}\right)$. The apparent trend of enhanced $\mathrm{Cu}$ (II) binding relative to $\mathrm{Zn}$ (II) is consistent with those observed for $\mathrm{N}$-donor functionalities within a range of flexible ligands..$^{25,86-88}$

Although the neutral form of PyBD is the major species in solution at physiological $\mathrm{pH}$ (vide supra), variable-pH UV-vis titrations were also conducted to elucidate complexation and binding properties of PyBD with $\mathrm{Cu}(\mathrm{II})$ in solution at ambient temperature and the proposed local $\mathrm{pH}$ for $\mathrm{Cu}(\mathrm{II})-\mathrm{A} \beta$ species ( $\mathrm{pH}=6.6)$ (Fig. 3, left). Based on the $\mathrm{p} K_{\mathrm{a}}$ value determined for PyBD and these titration results, the stability constants $(\log \beta)$ for the these complexes were determined to be 12.2(8) and 4.4(8) for $\mathrm{CuL}$ and $\mathrm{Cu}(\mathrm{LH})$, respectively. A solution speciation diagram was modeled using these stability constants and suggests complexation of PyBD with $\mathrm{Cu}$ (II) occurs in a $1: 1$ metal : ligand ratio. While neutral and protonated forms of $\mathrm{Cu}(\mathrm{II})-\mathbf{P y B D}$ may exist at different $\mathrm{pH}$ values, the data indicate that the neutral $\mathrm{Cu}(\mathrm{II})-\mathbf{P y B D}$ form is the major species at $\mathrm{pH} 6.6$ (Fig. 3, right). Additionally, the concentration of free $\mathrm{Cu}(\mathrm{II})$ in solution at $\mathrm{pH} 6.6$ yields a $p \mathrm{Cu}$ value of $8.3(4)(p \mathrm{Cu}=-\log$ $\left.[\mathrm{Cu}(\mathrm{II})]_{\text {unbound }}\right)$. The $p \mathrm{Cu}$ magnitude suggests an approximate $K_{\mathrm{d}}$ for $\mathrm{Cu}$ (II)-PyBD to be $c a$. nanomolar. When considered with the reported $K_{\mathrm{d}}$ values for $\mathrm{Cu}(\mathrm{II})-\mathrm{A} \beta$ species (picomolar to nanomolar range), ${ }^{4,5,17,19-21,24,89}$ this approximate dissociation constant indicates that PyBD may be able to compete for $\mathrm{Cu}(\mathrm{II})$ binding in $\mathrm{Cu}(\mathrm{II})-\mathrm{A} \beta$ species.

To estimate the ability of PyED to bind Cu(II) in the presence of other biologically relevant metal ions such as $\mathrm{Ca}(\mathrm{II}), \mathrm{Co}(\mathrm{II})$, $\mathrm{Fe}(\mathrm{II}), \mathrm{Fe}(\mathrm{III}), \mathrm{Mg}(\mathrm{II}), \mathrm{Mn}(\mathrm{II}), \mathrm{Ni}(\mathrm{II})$, and $\mathrm{Zn}(\mathrm{II})$, selectivity was evaluated for the unreactive model compound PyBD by a

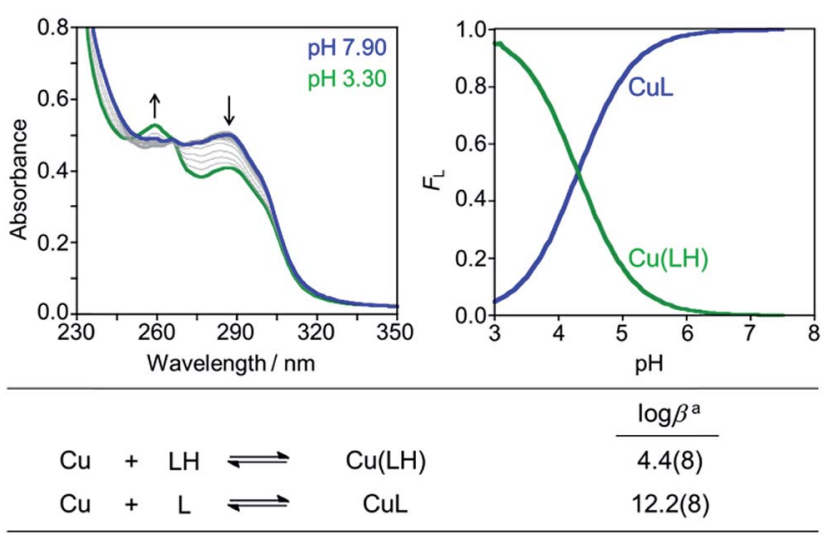

Fig. 3 Solution speciation of the Cu(॥)-PyBD complex. Left: UV-vis

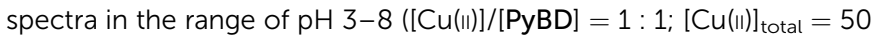
$\mu \mathrm{M})$. Right: solution speciation diagram $\left(F_{\mathrm{Cu}}=\right.$ fraction of free $\mathrm{Cu}$ and $\mathrm{Cu}$ complexes). Bottom: stability constants of the $\mathrm{Cu}(॥)-\mathrm{PyBD}$ complex with charges admitted for clarity. Titrations were performed at room temperature with $I=0.1 \mathrm{M} \mathrm{NaCl}$. ${ }^{\text {aError }}$ in the last digit is indicated in parentheses. 
competitive UV-vis absorption assay (Fig. S2†). Even in the presence of a large excess of competing metal ion, PyBD displays good selectivity for $\mathrm{Cu}(\mathrm{II})$ over $\mathrm{Ca}(\mathrm{II}), \mathrm{Co}(\mathrm{II}), \mathrm{Mg}$ (II), $\mathrm{Mn}(\mathrm{II})$, and Ni(II), while significant binding is shown in the presence of $\mathrm{Fe}(\mathrm{II})$ and $\mathrm{Fe}(\mathrm{III})$ (Fig. S2 $\dagger$ ). The observation that PyBD demonstrates selectivity for $\mathrm{Cu}$ (II) over $\mathrm{Zn}$ (II) leads to the expectation that modulation of $\mathrm{Cu}(\mathrm{II})$-bound $\mathrm{A} \beta$ species via metal chelation and subsequent radical generation by PyED may be more prominent than for the $\mathrm{Zn}$ (II)-bound species (vida infra). Overall, the tetradentate pyridine-imine binding moiety of PyBD and PyED may be desirable for reacting with $\mathrm{Cu}(\mathrm{II})-\mathrm{A} \beta$ species over other biologically relevant divalent metal ions.

\section{Effect of PyED and PyBD on metal-free and metal-triggered A $\beta$ aggregation in vitro}

In order to assess the ability of bifunctional PyED to modulate metal-induced $A \beta_{40}$ and $A \beta_{42}$ aggregation pathways, in vitro disaggregation and inhibition experiments were conducted (Scheme 1). ${ }^{32,79,80}$ For comparison to PyED reactivity, the influence of monofunctional PyBD on $\mathrm{A} \beta$ aggregation was also examined. Disaggregation assays were designed to investigate the potential of both PyED and PyBD to structurally alter preformed metal-free and metal-associated $A \beta$ aggregates (Fig. 4 and 5), while inhibition experiments probed the compounds' ability to control the formation of metal-free and metal-induced $\mathrm{A} \beta$ aggregates (Fig. $\mathrm{S} 3$ and $\mathrm{S} 4 \dagger$ ). The resultant $\mathrm{A} \beta$ species were characterized using gel electrophoresis followed by Western blot with an anti-A $\beta$ antibody (6E10), and morphological changes were monitored by transmission electron microscopy (TEM). ${ }^{32,80}$

For preformed metal-free and metal-associated $\mathrm{A} \beta_{40}$ and $\mathrm{A} \beta_{42}$ aggregates, PyED and PyBD exhibit differing disaggregation capabilities (Fig. 4 and 5). In the case of $\mathrm{Zn}$ (II)- and $\mathrm{Cu}(\mathrm{II})-$ $\mathrm{A} \beta_{40}$ samples treated with PyED, $\mathrm{A} \beta$ species with an increasing range of molecular weights (MW) are observed at both 37 and $43{ }^{\circ} \mathrm{C}$ between 2 and $8 \mathrm{~h}$, while a decrease in signal intensity occurs between 8 and $24 \mathrm{~h}$ for samples incubated at $37{ }^{\circ} \mathrm{C}$ (Fig. 4A, lanes 5 and 8). Interestingly, variable reactivity of PyED with preformed $\mathrm{Zn}$ (II)-A $\beta_{40}$ aggregates was detected at $43{ }^{\circ} \mathrm{C}$. Addition of PyED presented an increasing distribution of MW throughout the time course (Fig. 4A, lane 5). In contrast, treatment of metal-A $\beta_{40}$ samples with PyBD leads to the generation of lower MW species ( $\mathrm{MW} \leq 25 \mathrm{kDa}$ ) over the $24 \mathrm{~h}$ period (Fig. 4A, lanes 6 and 9). These data suggest that PyBD only

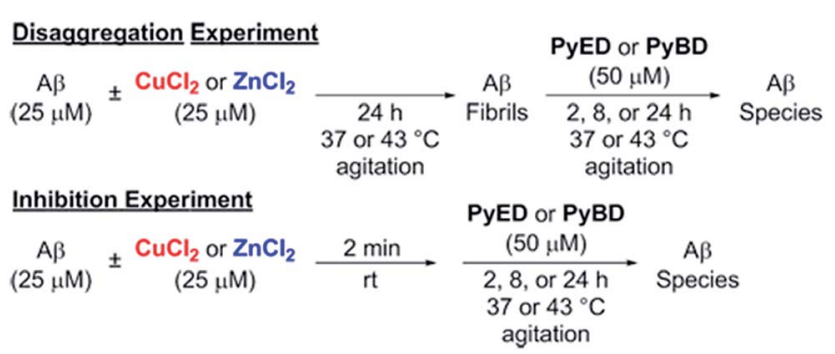

Scheme 1 Experimental set-up for $A \beta_{40}$ and $A \beta_{42}$ disaggregation and inhibition assays. slightly affects the transformation of preformed metal-A $\beta$ aggregates, indicating that the introduction of radical formation upon metal binding by PyED may be a key factor in the generation of metal-associated $\mathrm{A} \beta$ species exhibiting a different array of MW. Additionally, the reduction of gel band intensities in $\mathrm{Cu}(\mathrm{II})-\mathrm{A} \beta_{40}$ samples incubated with PyED for $24 \mathrm{~h}$ may imply the occurrence of further aggregation over time. These results are markedly different than those observed for metal-free samples incubated with PyED or PyBD which demonstrate overall minimal disaggregation activity, with the exception of $8 \mathrm{~h}$ incubation under hyperthermic conditions. This modest metal-free activity is expected due to the absence of both chelation and chelation-induced radical generation pathways (Fig. 4A, lane 2). In the absence of divalent metals, initiation of thermally-induced PyED cyclization is slow, ${ }^{64}$ leading to limited radical formation under these conditions.

The trends in the gel analysis are consistent with TEM images of preformed metal-A $\beta_{40}$ aggregates treated with PyED. At $37{ }^{\circ} \mathrm{C}$, TEM images of metal-A $\beta_{40}$ show a mixture of fibrillar and amorphous structure types, while at $43{ }^{\circ} \mathrm{C}$ amorphous $\mathrm{A} \beta$ morphologies are dominant. In comparison, parallel samples incubated with PyBD exhibit fibrillar structures similar to those under compound-free conditions at both temperatures (Fig. 4B and $\mathrm{C}$ ). Since PyED and PyBD show minimal change in the morphology of metal-free $A \beta_{40}$ aggregates relative to untreated samples, this suggests that variations in the fibrillar morphology may derive from chelation and chelation-induced radical mechanisms (Fig. 4B and C).

The ability of PyED and PyBD to transform preformed $\mathrm{A} \beta_{42}$ aggregates was also examined (Fig. 5). Relative to analogous $\mathrm{A} \beta_{40}$ samples, a similar trend in both PyED and PyBD reactivity with $A \beta_{42}$ was confirmed by gel electrophoresis. $A \beta_{42}$ species with a wide distribution of MW are observed with PyED-treated, metal-associated $A \beta_{42}$ aggregates over the course of $24 \mathrm{~h}$ at both temperatures (Fig. 5A, lanes 5 and 8), while low reactivity is visualized in metal-A $\beta_{42}$ samples incubated with PyBD (lanes 6 and 9). In the case of metal-free conditions, a slightly different ensemble of $\mathrm{A} \beta_{42} \mathrm{MW}$ are produced relative to the untreated control upon addition of PyED or PyBD (lanes 1-3). In addition to these trends, the TEM images reveal that analogous to $A \beta_{40}$, addition of PyED to metal-A $\beta_{42}$ samples induces changes in the morphology of preformed aggregates. Metal-treated $\mathrm{A} \beta_{42}$ exposed to either PyED or PyBD show thinner fibrils of various lengths ( 37 and $43{ }^{\circ} \mathrm{C}$ ), as well as more amorphous species $\left(37^{\circ} \mathrm{C}\right)$ than observed in compound-free samples (Fig. 5B and $\mathrm{C}$ ). As demonstrated for $\mathrm{A} \beta_{40}$, no distinct morphology changes are observed in the metal-free $A \beta_{42}$ samples treated with either ligand when compared to the untreated sample, indicating the importance of metal chelation in the disaggregation pathway.

In an effort to evaluate whether chelation and radical generation can influence fibril assembly, the effect of PyED and PyBD on modulation of the $A \beta$ aggregation pathway was investigated (Fig. S3 and $\mathrm{S} 4 \dagger$ ). Upon incubation of $\mathrm{Zn}$ (II) and $\mathrm{A} \beta_{40}$ with PyED, an increasing dispersion of various MW was visualized by gel analysis over prolonged exposures of up to $24 \mathrm{~h}$ (Fig. $\mathrm{S} 3, \dagger$ lane 5). In comparison, samples containing $\mathrm{Cu}(\mathrm{II})$, 
A

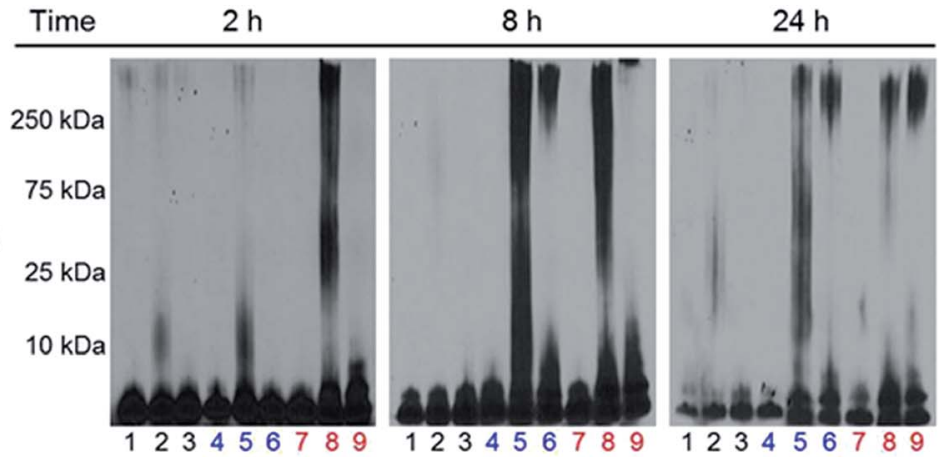

1. $A \beta$

2. $A \beta+$ PyED

3. $A \beta+P y B D$

4. $\mathrm{A} \beta+\mathrm{ZnCl}_{2}$

Time

$8 \mathrm{~h}$

5. $\mathrm{A} \beta+\mathrm{ZnCl}_{2}+\mathrm{PyED}$
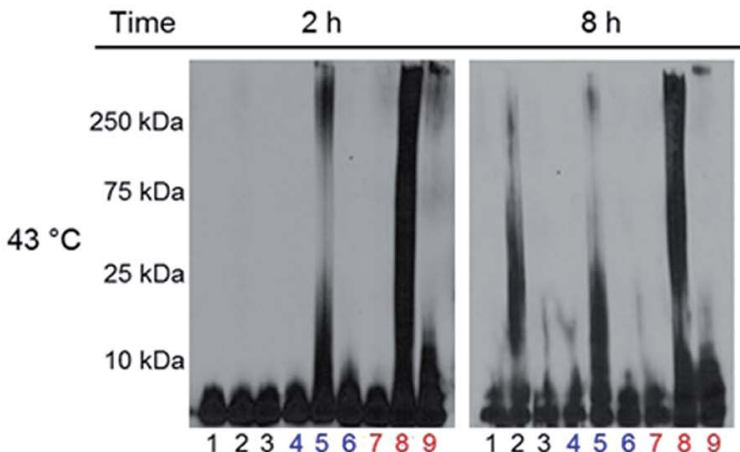

$24 \mathrm{~h}$

6. $\mathrm{A} \beta+\mathrm{ZnCl}_{2}+\mathrm{PyBD}$

7. $\mathrm{A} \beta+\mathrm{CuCl}_{2}$

8. $\mathrm{A} \beta+\mathrm{CuCl}_{2}+\mathrm{PyED}$

9. $\mathrm{A} \beta+\mathrm{CuCl}_{2}+\mathrm{PyBD}$

B

$A \beta_{40}$
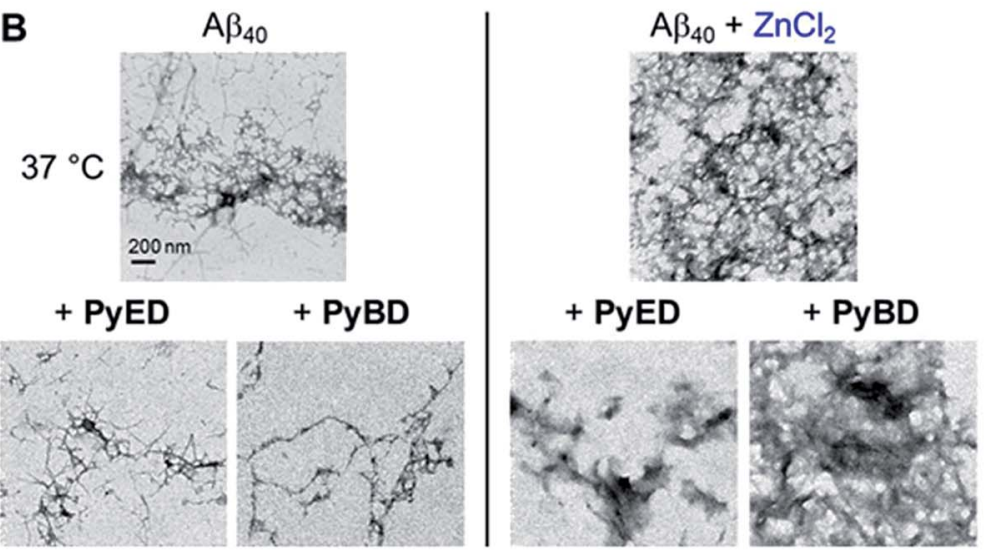

C

$A \beta_{40}$

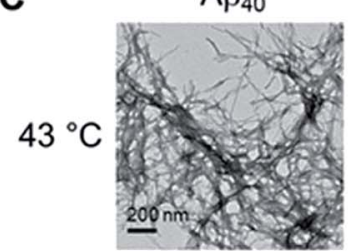

+ PyED

+ PyBD
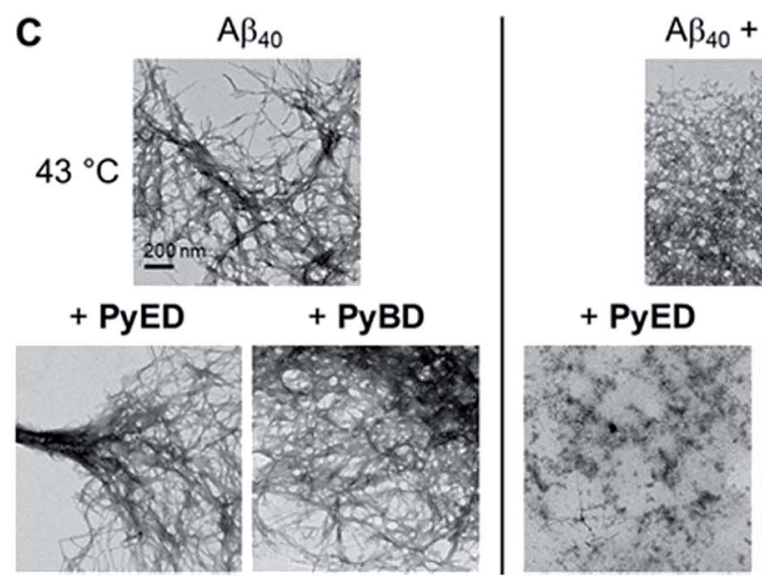

$\mathrm{A} \beta_{40}+\mathrm{ZnCl}_{2}$
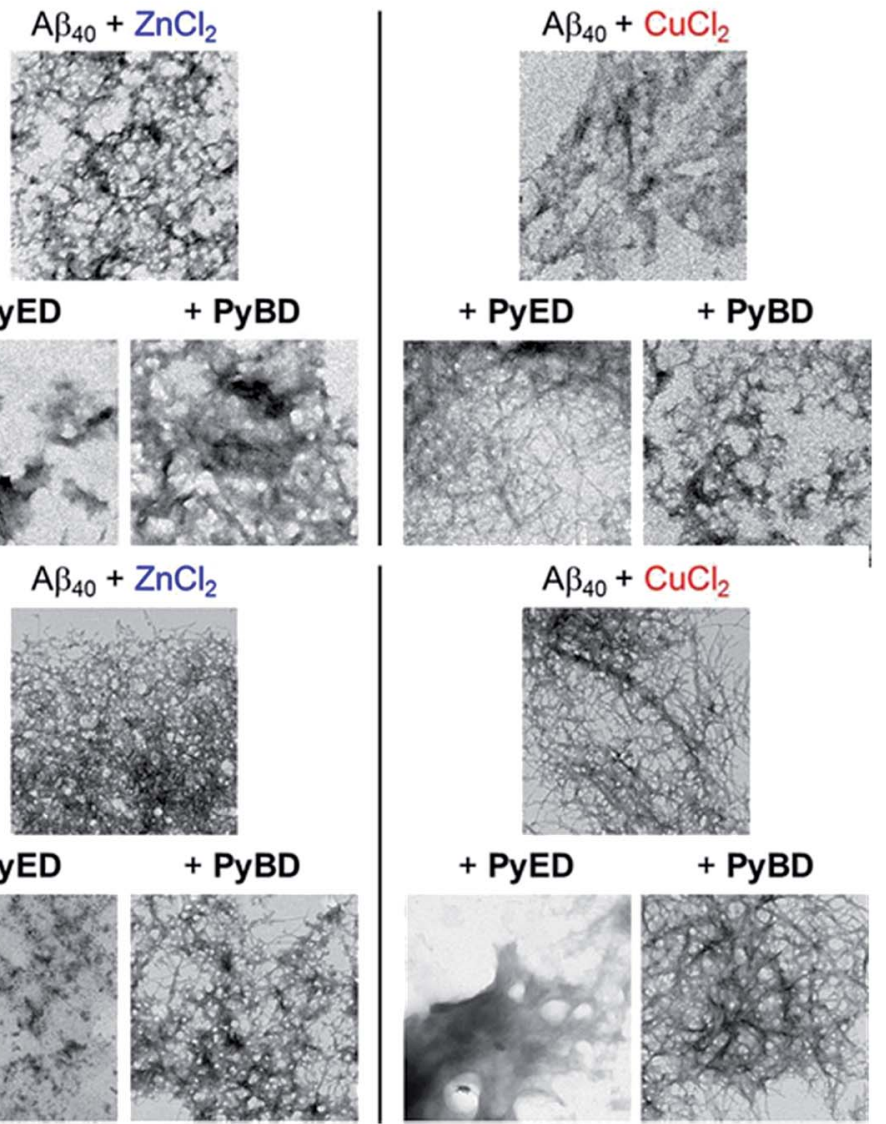

Fig. 4 Reactivity of PyED and PyBD with preformed $A \beta_{40}$ aggregates. (A) Analysis of resultant $A \beta_{40}$ species by gel electrophoresis with Western blot using an anti-A $\beta$ antibody (6E10). TEM images of the samples incubated for $24 \mathrm{~h}$ at (B) $37^{\circ} \mathrm{C}$ or (C) $43^{\circ} \mathrm{C}$. Experimental conditions: [A $\left.\beta\right]=25$ $\mu \mathrm{M} ;\left[\mathrm{CuCl}_{2}\right.$ or $\left.\mathrm{ZnCl}_{2}\right]=25 \mu \mathrm{M}$; [PyED or PyBD] $=50 \mu \mathrm{M} ; 2,8,24 \mathrm{~h}$ incubation at 37 or $43^{\circ} \mathrm{C}$; pH 7.4 (metal-free and $\left.\mathrm{Zn}(I)\right)$ or $\mathrm{pH} 6.6(\mathrm{Cu}(I))$; constant agitation. 

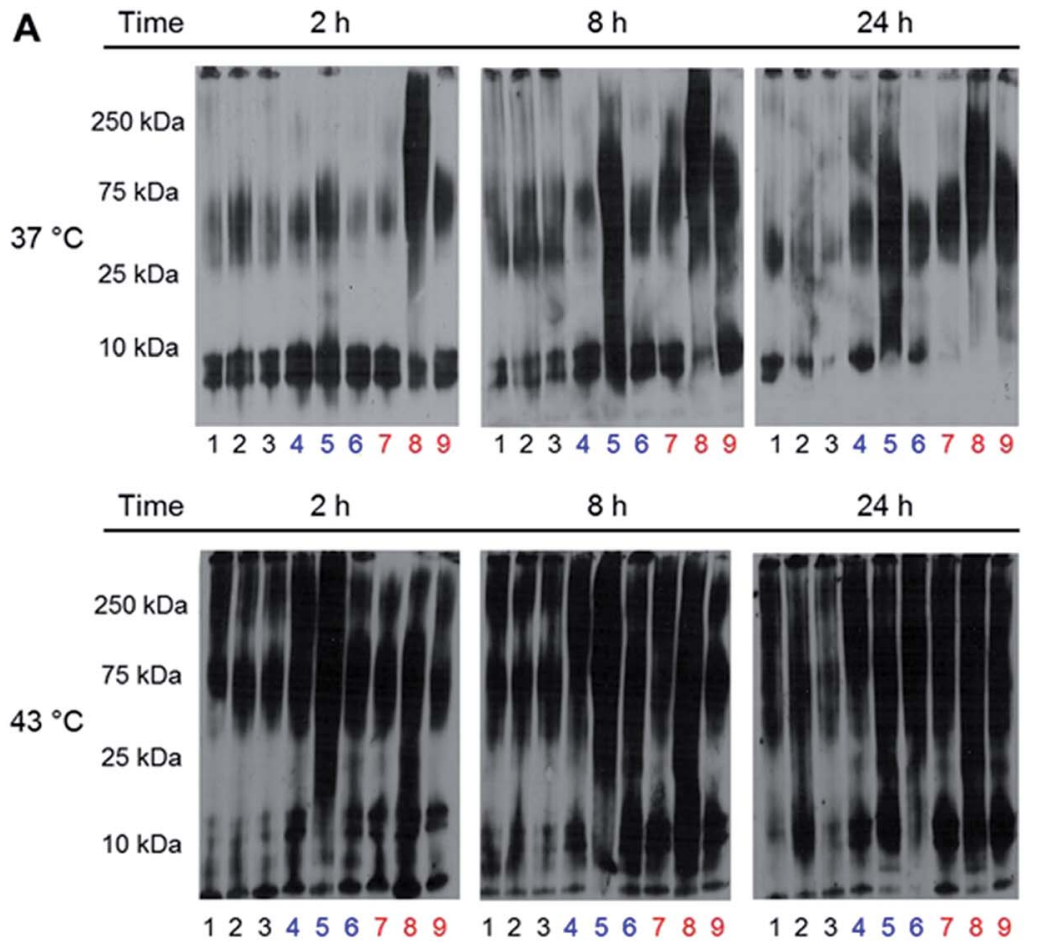
1. $A \beta$
2. $A \beta+$ PyED
3. $A \beta+P y B D$
4. $\mathrm{A} \beta+\mathrm{ZnCl}_{2}$
5. $\mathrm{A} \beta+\mathrm{ZnCl}_{2}+\mathrm{PyED}$
6. $\mathrm{A} \beta+\mathrm{ZnCl}_{2}+\mathrm{PyBD}$
7. $\mathrm{A} \beta+\mathrm{CuCl}_{2}$
8. $\mathrm{A} \beta+\mathrm{CuCl}_{2}+\mathrm{PyED}$
9. $\mathrm{A} \beta+\mathrm{CuCl}_{2}+\mathrm{PyBD}$

B

$A \beta_{42}$
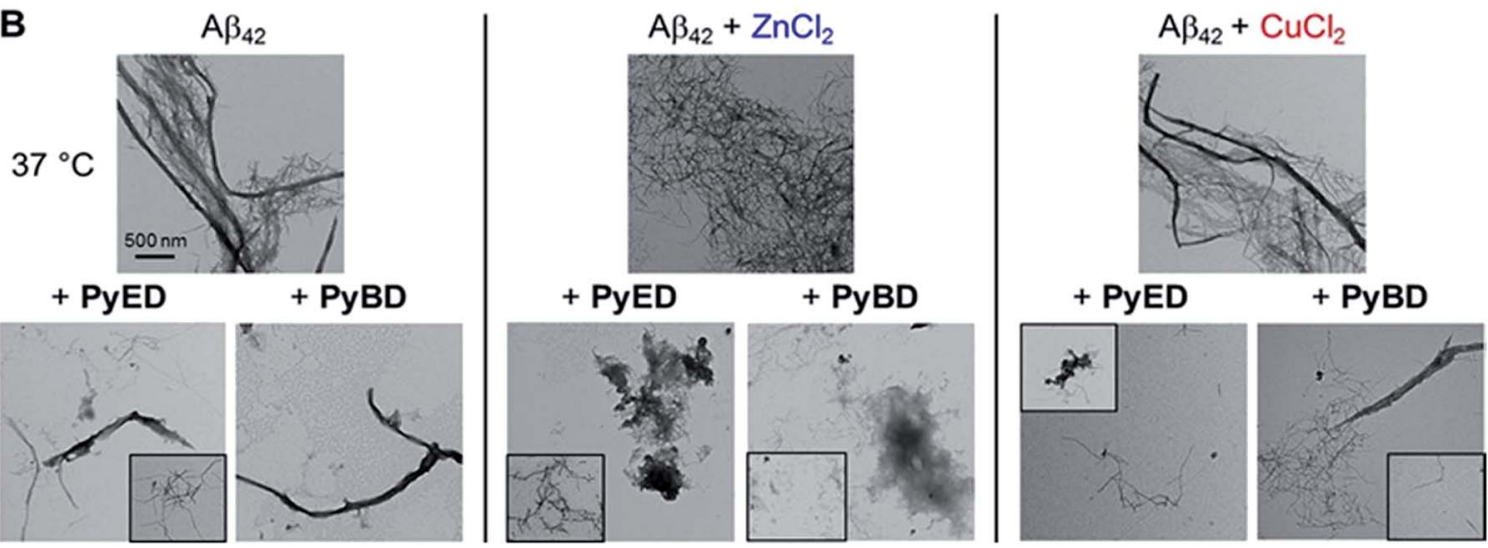

C

$A \beta_{42}$

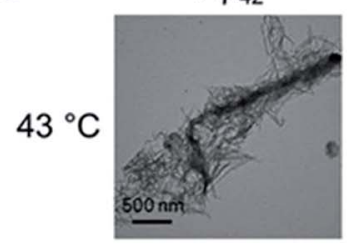

+ PyED

+ PyBD
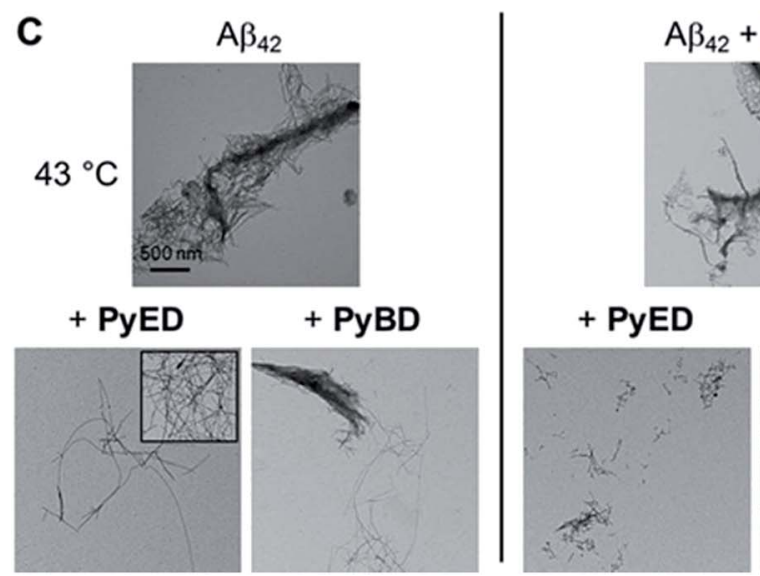

$\mathrm{A} \beta_{42}+\mathrm{ZnCl}_{2}$
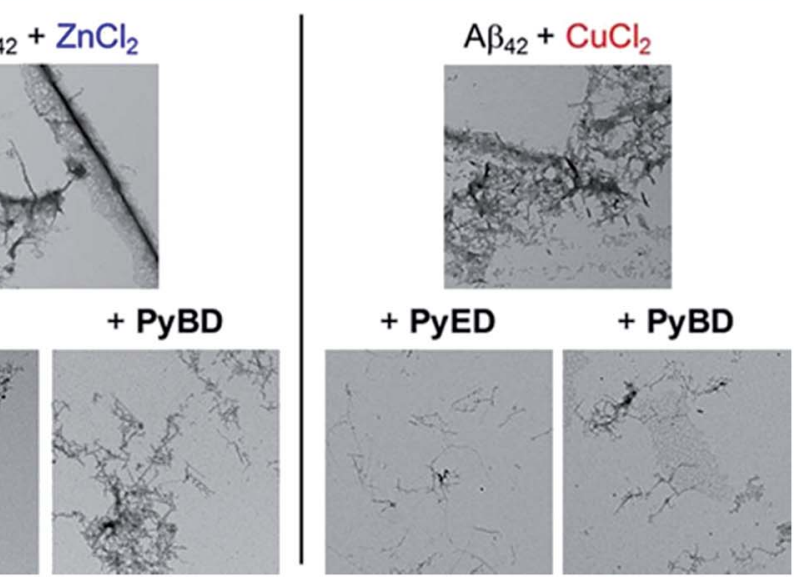

Fig. 5 (A) Analysis of resultant $A \beta_{42}$ species by gel electrophoresis with Western blot using an anti-A $\beta$ antibody (6E10). TEM images of samples incubated for $24 \mathrm{~h}$ at (B) $37^{\circ} \mathrm{C}$ or (C) $43^{\circ} \mathrm{C}$. Experimental conditions: $[\mathrm{A} \beta]=25 \mu \mathrm{M}$; $\left[\mathrm{CuCl}_{2}\right.$ or $\left.\mathrm{ZnCl}{ }_{2}\right]=25 \mu \mathrm{M}$; $[\mathrm{PyED}$ or PyBD] $=50 \mu \mathrm{M} ; 2,8,24 \mathrm{~h}$ incubation at 37 or $43^{\circ} \mathrm{C}$; $\mathrm{pH} 7.4$ (metal-free and $\mathrm{Zn}\left(\right.$ II)) or $\mathrm{pH} 6.6\left(\mathrm{Cu}\left({ }^{\prime \prime}\right)\right.$ ); constant agitation. 
$\mathrm{A} \beta_{40}$, and PyED generate different smearing patterns than those of the analogous $\mathrm{Zn}(\mathrm{II})-\mathrm{A} \beta_{40}$ samples (lanes 5 and 8). Similar to the disaggregation results, the gel band intensities of the $\mathrm{Cu}(\mathrm{II})-$ $\mathrm{A} \beta_{40}$ samples also decrease between 8 and $24 \mathrm{~h}$ incubation time at both 37 and $43{ }^{\circ} \mathrm{C}$, suggesting the possibility of further aggregation over long incubation times. The PyED inhibition activity compares favorably with that of PyBD, where only a slight modulation of the metal-induced aggregation pathway is observed (lanes 6 and 9), while exposure of metal-free $A \beta_{40}$ to either PyED or PyBD results in little to no activity (lanes 2 and 3). Thus, analogous to the disaggregation results, these data indicate that bifunctional PyED exhibits greater inhibition of metalinduced $A \beta$ aggregation compared to monofunctional PyBD. These findings are supported by TEM images of $A \beta_{40}$ samples incubated at $43{ }^{\circ} \mathrm{C}$ that reveal smaller, amorphous $\mathrm{A} \beta$ species in the presence of divalent metal ions and PyED (Fig. S3C $\dagger$ ). Importantly, no significant morphological changes are observed in the metal-free A $\beta$ samples exposed to either PyED or PyBD. As expected, the trend in the inhibition of $A \beta_{42}$ aggregation upon addition of PyED or PyBD is comparable to that of $\mathrm{A} \beta_{40}$ (Fig. S4†). Significant modification of the aggregation pathway is only visualized for metal-associated $A \beta$ species treated with PyED (Fig. S4A, $\dagger$ lanes 5 and 8). Additionally, TEM images reveal that thinner fibrils and/or amorphous aggregates are generated in PyED-treated metal-A $\beta_{42}$ samples compared to compound-free conditions (Fig. S4B and $\mathrm{C} \dagger$ ). Taken together, the disaggregation and inhibition results reveal the enhanced ability of PyED ( $v s$. PyBD) to variably modulate metal-free and metal-induced $\mathrm{A} \beta$ aggregation.

From the data available on a range of molecular structures, modulation of $A \beta$ species may derive from the differential interaction between the ligand frameworks and monomeric $A \beta$ peptide. ${ }^{4,30,32}$ To evaluate the degree of this interaction, $A \beta$ was incubated with PyED or control ligand PyBD at $0{ }^{\circ} \mathrm{C}$ for $2 \mathrm{~h}$ in a ratio of $6: 1$ ligand : $A \beta$ peptide $([\mathrm{A} \beta]=100 \mu \mathrm{M}){ }^{30}$ The resulting species were analyzed using native nanoelectrospray ionizationmass spectrometry by comparison to the established $A \beta$-interacting neuropeptide Leucine-enkephalin (Leu-enk). ${ }^{\mathbf{9 0}}$ No ligand-A $\beta$ species were detected and no significant differences were observed between the spectra obtained upon incubation with PyED or PyBD, suggesting neither ligand framework appreciably binds $\mathrm{A} \beta$ relative to Leu-enk.

Overall, the data suggest that the disparate capability of PyED to regulate $A \beta$ aggregation is due to a combination of metal extraction from $A \beta$, interaction of ligand with metalbound $A \beta$ species, and induction of radical-mediated modification of the peptide aggregation pathway. In support of the interaction of PyED and PyED with metal-bound A $\beta$ species at $43{ }^{\circ} \mathrm{C}$, photo-induced loss of $\mathrm{HCO}_{2}$ from $\mathrm{M}(\mathrm{II})-\mathrm{A} \beta$ disaggregation samples and subsequent loss of $\mathrm{CO}_{2}(\mathrm{Cu}(\mathrm{II})-\mathrm{A} \beta$ only) on the b-ions is observed by MALDI-TOF-TOF, whereas the corresponding $\mathrm{y}$-ions appear to be intact (Fig. S5 and Tables S1-S3†). Moreover, the $\mathrm{b}_{7}$ ion reveals that $\mathrm{CO}_{2}$ loss occurs N-terminal to aspartate, D7. In addition, MALDI-TOF data show that $\mathrm{HCO}_{2}$ loss is only operative upon incubation (4-8 h) of the components $\mathrm{A} \beta$, metal ion (Cu(II) or $\mathrm{Zn}(\mathrm{II})$ ), and ligand (PyBD or PyED) (Fig. S6-S8†). This loss of $\mathrm{HCO}_{2}$ from $\mathrm{M}(\mathrm{II})-\mathrm{A} \beta$ and subsequent loss of $\mathrm{CO}_{2}(\mathrm{Cu}$ (II)-A $\beta$ only) is also observed in the analogous 37 ${ }^{\circ} \mathrm{C}$ disaggregation samples (Fig. S9-S11†). Importantly, rapid addition of any of the pair of components with the same incubation time, or the mixture of three components with no incubation does not result in any detectable photo-induced loss of $\mathrm{CO}_{2}$. This indicates that metal and ligand must be co-localized within the metal binding consensus sequence (1-16) and is consistent with $\mathrm{CO}_{2}$ loss mechanisms from photo-induced redox and ESI electron capture/detachment of $\mathrm{Cu}$ and $\mathrm{Zn}$ bound peptides. ${ }^{\mathbf{9 1 - 9 4}}$

While evidence for the interaction among $A \beta$, metal ions, and PyED or PyBD is suggested for the A $\beta$ modulation pathway, and radical-induced peptide fragmentation as part of the overarching $A \beta$ degradation process is also proposed, detection of specific, low MW fragments is more elusive. Peptidic cleavage by $\alpha$-H-atom abstraction and subsequent detection of fragments by mass spectrometry is complicated by solvent accessibility and side-chain reactivity which diversify product distribution and reduce the abundances of individual species. The absence of individual peptide fragments, however, does not preclude radical damage to $A \beta$ as all of these radical reaction pathways will lead to structural changes in metal-bound $A \beta$ aggregates. Thus, the enhanced reactivity of PyED compared to PyBD towards metal-A $\beta$ species is reflective of the broader role radicals may play in the modulation of overall $A \beta$ structure.

\section{Conclusions}

Approaches to modulate the aggregation pathway are at the forefront of current small molecule designs for $\mathrm{AD}$ therapy. The ensemble of existing methodologies encompasses metal chelation and interruption of peptide aggregation by ligand interaction with $\mathrm{A} \beta$, as well as targeting metal-A $\beta$ ternary complex formation as disruption mechanisms. Here we demonstrate a bifunctional approach that combines metal chelation and active radical generation to affect $A \beta$ aggregation. Our results indicate that the ligand-metal-A $\beta$ interaction with subsequent radical generation is a relatively rapid $\left(2 \mathrm{~h}\right.$ at $\left.43{ }^{\circ} \mathrm{C}\right)$ mechanism for influencing $A \beta$ structural integrity and thus, the aggregation pathway. This outcome may lead to new hybrid molecular constructs designed to take advantage of several $A \beta$ interaction modes in order to achieve rapid $A \beta$ species modulation.

\section{Acknowledgements}

This work is supported by the National Science Foundation (CHE-1265703) (to J.M.Z.); the Ruth K. Broad Biomedical Foundation, the DGIST R\&D Program of the Ministry of Science, ICT and Future Planning of Korea (14-BD-0403), and the National Research Foundation of Korea grant funded by the Korean government (MSIP) (NRF-2014R1A2A2A01004877) (to M.H.L.). The authors thank Joan M. Walker for acquiring the $\mathrm{A} \beta_{40}$ TEM images. 


\section{Notes and references}

1 Alzheimer's Association, Alzheimers Dement., 2012, 8, 131168.

2 F. M. LaFerla, K. N. Green and S. Oddo, Nat. Rev. Neurosci., 2007, 8, 499-509.

3 R. Jakob-Roetne and H. Jacobsen, Angew. Chem., Int. Ed., 2009, 48, 3030-3059.

4 K. P. Kepp, Chem. Rev., 2012, 112, 5193-5239.

5 M. G. Savelieff, A. S. DeToma, J. S. Derrick and M. H. Lim, Acc. Chem. Res., 2014, 47, 2475-2482.

6 Y. Miller, B. Ma and R. Nussinov, Chem. Rev., 2010, 110, 4820-4838.

7 K. Blennow, M. J. de Leon and H. Zetterberg, Lancet, 2006, 368, 387-403.

8 M. P. Mattson, Nature, 2004, 430, 631-639.

9 E. Karran, M. Mercken and B. De Strooper, Nat. Rev. Drug Discovery, 2011, 10, 698-712.

10 M. F. Galindo, I. Ikuta, X. Zhu, G. Casadesus and J. Jordan, J. Neurochem., 2010, 114, 933-945.

11 J. P. Blass, Ann. N. Y. Acad. Sci., 2000, 924, 170-183.

12 M. Dumont and M. F. Beal, Free Radical Biol. Med., 2011, 51, 1014-1026.

13 K. J. Barnham and A. I. Bush, Curr. Opin. Chem. Biol., 2008, 12, 222-228.

14 A. I. Bush, W. H. Pettingell, G. Multhaup, M. d. Paradis, J.-P. Vonsattel, J. F. Gusella, K. Beyreuther, C. L. Masters and R. E. Tanzi, Science, 1994, 265, 1464-1467.

15 A. I. Bush, Trends Neurosci., 2003, 26, 207-214.

16 B. R. Roberts, T. M. Ryan, A. I. Bush, C. L. Masters and J. A. Duce, J. Neurochem., 2012, 120, 149-166.

17 L. E. Scott and C. Orvig, Chem. Rev., 2009, 109, 4885-4910.

18 E. L. Que, D. W. Domaille and C. J. Chang, Chem. Rev., 2008, 108, 1517-1549.

19 P. Faller, ChemBioChem, 2009, 10, 2837-2845.

20 J. A. Duce and A. I. Bush, Prog. Neurobiol., 2010, 92, 1-18.

21 A. S. DeToma, S. Salamekh, A. Ramamoorthy and M. H. Lim, Chem. Soc. Rev., 2012, 41, 608-621.

22 P. Zatta, D. Drago, S. Bolognin and S. L. Sensi, Trends Pharmacol. Sci., 2009, 30, 346-355.

23 P. Faller and C. Hureau, Dalton Trans., 2009, 1080-1094.

24 M. A. Telpoukhovskaia and C. Orvig, Chem. Soc. Rev., 2013, 42, 1836-1846.

25 R. A. Cherny, C. S. Atwood, M. E. Xilinas, D. N. Gray, W. D. Jones, C. A. McLean, K. J. Barnham, I. Volitakis, F. W. Fraser, Y.-S. Kim, X. Huang, L. E. Goldstein, R. D. Moir, J. T. Lim, K. Beyreuther, H. Zheng, R. E. Tanzi, C. L. Masters and A. I. Bush, Neuron, 2001, 30, 665-676.

26 P. J. Crouch, D. J. Tew, T. Du, D. N. Nguyen, A. Caragounis, G. Filiz, R. E. Blake, I. A. Trounce, C. P. W. Soon, K. Laughton, K. A. Perez, Q.-X. Li, R. A. Cherny, C. L. Masters, K. J. Barnham and A. R. White, J. Neurochem., 2009, 108, 1198-1207.

27 C. W. Ritchie, A. I. Bush, A. Mackinnon, et al., Arch. Neurol., 2003, 60, 1685-1691.
28 L. Lannfelt, K. Blennow, H. Zetterberg, S. Batsman, D. Ames, J. Harrison, C. L. Masters, S. Targum, A. I. Bush, R. Murdoch, J. Wilson and C. W. Ritchie, Lancet Neurol., 2008, 7, 779-786. 29 N. G. Faux, C. W. Ritchie, A. Gunn, A. Rembach, A. Tsatsanis, J. Bedo, J. Harrison, L. Lannfelt, K. Blennow, H. Zetterberg, M. Ingelsson, C. L. Masters, R. E. Tanzi, J. L. Cummings, C. M. Herd and A. I. Bush, J. Alzheimer's Dis., 2010, 20, 509-516.

30 A. S. Pithadia, A. Kochi, M. T. Soper, M. W. Beck, Y. Liu, S. Lee, A. S. DeToma, B. T. Ruotolo and M. H. Lim, Inorg. Chem., 2012, 51, 12959-12967.

31 C. Rodríguez-Rodríguez, M. Telpoukhovskaia and C. Orvig, Coord. Chem. Rev., 2012, 256, 2308-2332.

32 J. J. Braymer, J.-S. Choi, A. S. DeToma, C. Wang, K. Nam, J. W. Kampf, A. Ramamoorthy and M. H. Lim, Inorg. Chem., 2011, 50, 10724-10734.

33 Y. Liu, A. Kochi, A. S. Pithadia, S. Lee, Y. Nam, M. W. Beck, X. He, D. Lee and M. H. Lim, Inorg. Chem., 2013, 52, 81218130.

34 S. Lee, X. Zheng, J. Krishnamoorthy, M. G. Savelieff, H. M. Park, J. R. Brender, J. H. Kim, J. S. Derrick, A. Kochi, H. J. Lee, C. Kim, A. Ramamoorthy, M. T. Bowers and M. H. Lim, J. Am. Chem. Soc., 2014, 136, 299-310.

35 M. B. Goshe, Y. H. Chen and V. E. Anderson, Biochemistry, 2000, 39, 1761-1770.

36 A. P. Breen and J. A. Murphy, Free Radical Biol. Med., 1995, 18, 1033-1077.

37 L.-W. Wang and M. R. Chance, Anal. Chem., 2011, 83, 72347241.

38 G. Xu and M. R. Chance, Chem. Rev., 2007, 107, 3514-3543. 39 C. L. Hawkins and M. J. Davies, Biochim. Biophys. Acta, Bioenerg., 2001, 1504, 196-219.

40 W. S. Bowen, W. E. Hill and J. S. Lodmell, Methods, 2001, 25, 344-350.

41 H. Eguchi, Y. Ikeda, S. Koyota, K. Honke, K. Suzuki, J. M. C. Gutteridge and N. Taniguchi, J. Biochem., 2002, 131, 477-484.

42 S. Basak and V. Nagaraja, Nucleic Acids Res., 2001, 29, E105. 43 T. Kowalik-Jankowska, M. Ruta, K. Wisniewska, L. Lankiewicz and M. Dyba, J. Inorg. Biochem., 2004, 98, 940-950.

44 E. Heyduk and T. Heyduk, Biochemistry, 1994, 33, 9643-9650. 45 E. R. Stadtman, Annu. Rev. Biochem., 1993, 62, 797-821.

46 S. D. Maleknia and K. M. Downard, Chem. Soc. Rev., 2014, 43, 3244-3258.

47 C. L. Hawkins and M. J. Davies, J. Chem. Soc., Perkin Trans. 2, 1998, 2617-2622.

48 D. T. Sawyer, Coord. Chem. Rev., 1997, 165, 297-313.

49 M. Strlic, J. Kolar, V.-S. Selih, D. Kocar and B. Pihlar, Acta Chim. Slov., 2003, 50, 619-632.

50 G. P. Anipsitakis and D. D. Dionysiou, Environ. Sci. Technol., 2004, 38, 3705-3712.

51 J. A. Simpson, K. H. Cheeseman, S. E. Smith and R. T. Dean, Biochem. J., 1988, 254, 519-523.

52 N. K. Urbanski and A. Beresewicz, Acta Biochim. Pol., 2000, 47, 951-962. 
53 B. D. Schmidt and C. F. Meares, Biochemistry, 2002, 41, 41864192.

54 K. B. Hall and R. O. Fox, Methods, 1999, 18, 78-84.

55 M. A. Trakselis, S. C. Alley and F. T. Ishmael, Bioconjugate Chem., 2005, 16, 741-750.

56 G. M. Heilek and H. F. Noller, Science, 1996, 272, 1659-1662.

57 L. Lancaster, M. C. Kiel, A. Kaji and H. F. Noller, Cell, 2002, 111, 129-140.

58 P. A. MacFaul, D. D. M. Wayner and K. U. Ingold, Acc. Chem. Res., 1998, 31, 159-162.

59 W. M. Garrison, Chem. Rev., 1987, 87, 381-398.

60 R. T. Dean, S. P. Wolff and M. A. McElligott, Free Radical Res. Commun., 1989, 7, 97-103.

61 M. J. Davies, Arch. Biochem. Biophys., 1996, 336, 163-172.

62 E. R. Stadtman, Methods Enzymol., 1995, 258, 379-393.

63 C. J. Easton, Chem. Rev., 1997, 97, 53-82.

64 D. S. Rawat and J. M. Zaleski, J. Am. Chem. Soc., 2001, 123, 9675-9676.

65 T. Chandra, R. A. Allred, B. J. Kraft, L. M. Berreau and J. M. Zaleski, Inorg. Chem., 2004, 43, 411-420.

66 S. E. Lindahl, H. Park, M. Pink and J. M. Zaleski, J. Am. Chem. Soc., 2013, 135, 3826-3833.

67 P. J. Benites, R. C. Holmberg, D. S. Rawat, B. J. Kraft, L. J. Klein, D. G. Peters, H. H. Thorp and J. M. Zaleski, J. Am. Chem. Soc., 2003, 125, 6434-6446.

68 B. J. Kraft, N. L. Coalter, M. Nath, A. E. Clark, A. R. Siedle, J. C. Huffman and J. M. Zaleski, Inorg. Chem., 2003, 42, 1663-1672.

69 J. M. Walker, L. Gou, S. Bhattacharyya, S. E. Lindahl and J. M. Zaleski, Chem. Mater., 2011, 23, 5275-5281.

70 S. M. Routt, J. Zhu, J. M. Zaleski and J. R. Dynlacht, Int. J. Hyperthermia, 2011, 27, 435-444.

71 W. C. Dewey, S. A. Sapareto and D. A. Betten, Radiat. Res., 1978, 76, 48-59.

72 P. M. Corry, S. Robinson and S. Getz, Radiology, 1977, 123, 475-482.

73 E. Dikomey and J. Franzke, Int. J. Radiat. Biol., 1992, 61, 221233.

74 R. S. L. Wong, J. R. Dynlacht, B. Cedervall and W. C. Dewey, Int. J. Radiat. Biol., 1995, 68, 141-152.

75 W. L. Titsworth, G. J. A. Murad, B. L. Hoh and M. Rahman, Anticancer Res., 2014, 34, 565-574.
76 D. M. Welsh, Crit. Care Nurs. Clin., 1995, 7, 115-123.

77 M. H. Falk and R. D. Issels, Int. J. Hyperthermia, 2001, 17, 118.

78 Y. Anzai, R. Lufkin, A. DeSalles, D. R. Hamilton, K. Farahani and K. L. Black, Am. J. Neuroradiol., 1995, 16, 39-48.

79 C. Rodriguez-Rodriguez, N. Sanchez de Groot, A. Rimola, A. Alvarez-Larena, V. Lloveras, J. Vidal-Gancedo, S. Ventura, J. Vendrell, M. Sodupe and P. Gonzalez-Duarte, J. Am. Chem. Soc., 2009, 131, 1436-1451.

80 A. K. Sharma, S. T. Pavlova, J. Kim, D. Finkelstein, N. J. Hawco, N. P. Rath, J. Kim and L. M. Mirica, J. Am. Chem. Soc., 2012, 134, 6625-6636.

81 L. Di, E. H. Kerns, K. Fan, O. J. McConnell and G. T. Carter, Eur. J. Med. Chem., 2003, 38, 223-232.

82 A. Avdeef, S. Bendels, L. Di, B. Faller, M. Kansy, K. Sugano and Y. Yamauchi, J. Pharm. Sci., 2007, 96, 2893-2909.

83 D. E. Clark and S. D. Pickett, Drug Discovery Today, 2000, 5, 49-58.

84 C. A. Lipinski, F. Lombardo, B. W. Dominy and P. J. Feeney, Adv. Drug Delivery Rev., 2001, 46, 3-26.

85 BBB Protocol and Test Compounds, pIon, Inc., Woburn, MA, 2009.

86 J. Masuoka, J. Hegenauer, B. R. Van Dyke and P. Saltman, J. Biol. Chem., 1993, 268, 21533-21537.

87 L. D. Pettit and J. L. M. Swash, J. Chem. Soc., Dalton Trans., 1976, 588-594.

88 H. Zhang, C.-S. Liu, X.-H. Bu and M. Yang, J. Inorg. Biochem., 2005, 99, 1119-1125.

89 E. Gaggelli, H. Kozlowski, D. Valensin and G. Valensin, Chem. Rev., 2006, 106, 1995-2044.

90 M. T. Soper, A. S. DeToma, S.-J. Hyung, M. H. Lim and B. T. Ruotolo, Phys. Chem. Chem. Phys., 2013, 15, 8952-8961.

91 J. Coon, J. Shabanowitz, D. Hunt and J. P. Syka, J. Am. Soc. Mass Spectrom., 2005, 16, 880-882.

92 E. Bagheri-Majdi, Y. Ke, G. Orlova, I. K. Chu, A. C. Hopkinson and K. W. M. Siu, J. Phys. Chem. B, 2004, 108, 11170-11181.

93 R. E. Bossio, R. R. Hudgins and A. G. Marshall, J. Phys. Chem. B, 2003, 107, 3284-3289.

94 T.-Y. Huang, J. F. Emory, R. A. J. O'Hair and S. A. McLuckey, Anal. Chem., 2006, 78, 7387-7391. 